\title{
MODELING THE DYNAMICS OF THE PRODUCTION PROCESS IN THE CONDITIONS OF UNCERTAINTY WITH THE USE OF THE CALCULUS OF VARIATIONS
}

Stefan Grzesiak, Ph.D., Associate Prof.

University of Szczecin

Faculty of Economics and Management

Department of Operations Research and Applied Mathematics in Economics

Mickiewicza 64, 71-101 Szczecin, Poland

e-mail: stefan.grzesiak@usz.edu.pl

Received 10 November 2015, Accepted 27 June 2016

\begin{abstract}
The article examines the possibility of applying elements of the calculus of variations to determine the quasioptimum distribution of production at the time in terms of stochastic. The discussion concerns the problems of modeling the distribution of production in a situation where we are dealing with a single product. Then, it has been generalized to a larger number of simultaneously produced ranges. In summary, it was the topic of the proposed methods possibilities of applications in practice firms.
\end{abstract}

Keywords: calculus of variations, stochastic modeling, distribution of production at the time

JEL classification: $\mathrm{C} 44$ 


\section{Introduction}

In the article of Grzesiak (2014), the analysis of the possibilities of applying the calculus of variations for the optimisation of the distribution of production into sub-periods in deterministic conditions was performed. The term "deterministic conditions" means that the decision maker has full knowledge about the demand for a specific product, and also has the possibility of using this knowledge in the future for forecasting. Although such a general assumption is convenient for a theorist, and desirable by practitioners, from the point of view of the possibility of obtaining the effective solution, it is rather unrealistic in the real economics. Therefore, while expanding this interesting and important thread of considerations, it would be worth analysing, if, in what conditions, and to what degree, the relaxing of these assumptions and the adoption of a stochastic approach would allow to obtain a suboptimal solution, because on such conditions there is no possibility to obtain a strictly optimal solution. It results from the necessity to accept the assumptions about the demand distribution that are difficult in unequivocal verification. These considerations constitute the main part of the article.

The goal of a production company that received orders for certain products assortments is to obtain close to optimal production arrangement in time, and to bear the smallest possible own costs. The manner in which it will be performed depends on the management organisational skills and the application of the appropriate quantitative methods for decision making. The conditions of uncertainty are certainly more difficult and less predictable, but much closer to reality. The new possibilities of the description of production dynamics, and searching for suboptimal solutions could be given by the calculus of variations. ${ }^{1}$ Then, it would be interesting to analyse, if and how in a certain situation the elements of the calculus of variations could be used.

\section{Construction of a decision problem in the case of one ordered product}

Let us assume that the demand for a certain product in the period $(0, t)$ is a random variable $V(t)=\int_{0}^{t} v(t) d t$ with a known probability distribution $\Phi[V(t)]$, while $v(t)$ means the demand in the moment $t$. Let us assume also that the total production in this period would be denoted as, $X(t)=\int_{0}^{t} x(t) d t$, if $x(t)$ denotes the production in the moment $t$. Similarly as in Grzesiak (2014), let us assume that holding the cost is constant and is denoted by $h$. However, in the conditions of uncertainty it should be assumed that in some time intervals shortages may occur. In order to consider the costs connected to this factor, a unit shortage cost, denoted by $b$, is introduced.

\footnotetext{
1 The idea and basics of calculus of variations are presented in Gelfand and Fomin (1975) and Nowoczesne kompendium matematyki (2004).
} 
The criterion of the decision problem is the minimisation of the total expected production costs in the analysed period, denoted by means of the function $f[x(t)]$, holding and shortage costs. ${ }^{2}$ The possible initial inventory of the product is denoted by $Z(0)$.

If $X(t)+Z(0) \geq V(t)$, then the total cost in the moment $t$ is:

$$
D(t)=f[x(t)]+h[X(t)-V(t)+Z(0)]
$$

and if $X(t)+Z(0)<V(t)$, then

$$
D(t)=f[x(t)]+b[V(t)-X(t)-Z(0)]
$$

The expected total cost in the moment $t$ equals:

$$
\begin{aligned}
E D(t)= & f[x(t)]+h \int_{-\infty}^{X(t)+Z(0)}[X(t)-V(t)+Z(0)] \Phi[V(t)] d V(t)+ \\
& +b \int_{X(t)+Z(0)}^{+\infty}[V(t)-X(t)-Z(0)] \Phi[V(t)] d V(t)
\end{aligned}
$$

The problem of the dynamic programming of production for the whole analysed period of time $(0, T)$ is as follows:

$$
\begin{gathered}
D=E \int_{0}^{T} D(t) d t=\int_{0}^{T} f[x(t)] d t+h \int_{-\infty}^{X(t)+Z(0)}[X(t)-V(t)+Z(0)] \Phi[V(t)] d V(t)+ \\
+b \int_{X(t)+Z(0)}^{+\infty}[V(t)-X(t)-Z(0)] \Phi[V(t)] d V(t) \rightarrow \text { min }
\end{gathered}
$$

The first part of formula (4) stands for the function of the production costs in the period $(0, T)$. The second one is the expected total holding cost, and the third one - the expected total shortage cost in the same period. The infinite limits in (4) can be replaced by the finite ones, if the maximum and minimum value of the random variable $V(t)$ is known. It is obvious that the minimum demand value is 0 , and the maximum one should be set up on the level of the company's production capabilities.

We look for the form of the $x(t)$ function, describing the distribution of production into sub-periods (in time).

\footnotetext{
2 The expected shortage costs can be estimated if the company has the information about losses being the result of delays or lack of deliveries in the past (e.g. penalties, starting the production in specific conditions, overtime work, etc.).
} 
We will try to find the solution of (4) by means of the calculus of variations. The righthand side of (4) is the integral of the $J=\int_{a}^{b} F\left[X(t), X^{\prime}(t), t\right] d t$ type. It reaches minimum when the Euler's differential equation is satisfied (Gelfand, Fomin, 1975, p. 23; Lange, 1967, p. 261):

$$
\frac{\partial F}{\partial X} \quad \frac{d}{d t} \frac{\partial F}{\partial X}
$$

The left-hand side of the Euler's equation for (4) can be calculated as follows:

$$
\frac{\partial F}{\partial X}=h \int_{-\infty}^{X(t)+Z(0)} \Phi\left[V(t) d V(t)-b \int_{X(t)+Z(0)}^{+\infty} \Phi[V(t) d V(t)\right.
$$

The right-hand side equals $\frac{d}{d t} f^{\prime}\left[X^{\prime}(t)\right]$ or $f^{\prime \prime}[x(t)] x^{\prime}(t)$. Equating both sides, we obtain the following equation:

$$
h \int_{-\infty}^{X(t)+Z(0)} \Phi\left[V(t) d V(t)-b \int_{X(t)+Z(0)}^{+\infty} \Phi\left[V(t) d V(t)=f^{\prime \prime}[x(t)] x^{\prime}(t)\right.\right.
$$

Solving equation (6), we obtain $x^{\prime}(t)$, and subsequently $X(t)$. Interpreting the obtained results, we can see that the first integral in (6) expresses the probability that the demand in the period $(0, t)$ will be smaller than the sum of the production and initial inventory, while the second one is the probability that the demand in the period $(0, t)$ will exceed $X(t)+Z(0)$, or the shortages will occur. The sum of both integrals equals 1 , and the whole left-hand side of (6) is the expected total holding and the shortage cost.

The integral $\int_{X(t)+Z(0)}^{+\infty} \Phi[V(t) d V(t)$ can be treated as the function of the lower integration limit and denoted as $\mathrm{P}[X(t)+Z(0)]$. Therefore, the equation (6) can be written as the condition:

$$
h\{1-P[X(t)+Z(0)]\}-b P[X(t)+Z(0)]=f^{\prime \prime}[x(t)] x^{\prime}(t)
$$

and

$$
P[X(t)+Z(0)]=(h+b)^{-1}\left\{h-f^{\prime \prime}[x(t)] x^{\prime}(t)\right\}
$$

The expression (8) is the optimum coefficient of the shortage risk for the analysed product. The component of the numerator leads to the smoothing of the production and the creation of an 
inventory. Its transformation enables to obtain the function of the distribution of the production in time:

$$
x^{\prime}(t)=\left\{f^{\prime \prime}[x(t)]\right\}^{-1}\{a-(a+b) P[X(t)+Z(0)]\}
$$

The solution of (9) and finding the function $x(t)$ requires the knowledge of the function of the total demand $\Phi[V(t)]$. It can be found on the basis of the past data if the nature of the production will not change, and the statistical data referring to the past demand is sufficiently reliable. Then, the probability distribution function $v(t)$, determining the demand in the moment $t$, can be treated as known. Let it be denoted by $\varphi[v(t)]$. On its basis, the probability distribution of $\Phi[V(t)]$ of the random variable $V(t)$ can be estimated.

After accepting the assumption that the demand in the subsequent moments of time are independent, the characteristic function of the sum of the random variables $V(t)$ will be the product of the characteristic functions of the variables $v(t)$. Let us write the characteristic function of the random variable $v(t)$ with the distribution $\varphi[v(t)]$ :

$$
X_{\varphi}(\tau, t)=\int_{-\infty}^{+\infty} \varphi(v) \exp (i \tau v) d v
$$

Remembering that $v(t)$ is the continuous function of the variable $t$, and that the logarithm of the characteristic function of the independent random variables equals the sum of the logarithms of the characteristic functions of these variables, the characteristic function of the random variable $V(t)$ can be written, as:

$$
\ln X_{\Phi}(\tau, t)=\int_{-\infty}^{+\infty} \ln X_{\varphi}(\tau, t) d t
$$

Knowing the expression (11), the probability distribution of $V(t)$ can be found by means of the appropriate Fourier transformation:

$$
\Phi[V(t)]=(2 \pi)^{-0,5} \int_{-\infty}^{+\infty} X_{\Phi}(\tau, t) \exp (-i \tau \nu) d \tau
$$

Since $X_{\Phi}(\tau, t)=\exp \left[\int_{0}^{t} \ln X_{\varphi}(\tau, t) d t\right]$, we obtain:

$$
\Phi[V(t)]=(2 \pi)^{-0,5} \int_{-\infty}^{+\infty} \exp \left[\int_{0}^{\mathrm{t}} \ln \mathrm{X}_{\mathrm{o}}(\tau, t) d t-i v \tau\right] d \tau
$$


We can estimate the probability distribution of the variable $V(t)$, if $v(t)$ is normally distributed with the mathematical expectation $\mu(t)$ and variance $\sigma^{2}(t)$. Therefore, the variable $V(t)$ is also normally distributed: ${ }^{3}$

$$
V(t) \sim N\left[\int_{0}^{t} \mu(t) d t, \int_{0}^{t} \sigma^{2}(t)\right]
$$

Referring to the analysed decision model of the programming of the production and the inventories in time, and using equations (7) and (4), we can write: ${ }^{4}$

$$
1-P[X(t)+Z(0)]=\left[2 \pi \int_{0}^{t} \sigma^{2}(t) d t\right]^{-0.5} \int_{0}^{X(t)+Z(0)} \exp \left\{-\frac{\left[V(t)-\int_{0}^{t} \mu(t) d t\right]^{2}}{2 \int_{0}^{t} \sigma^{2}(t) d t}\right\} d V(t)
$$

and it follows that:

$$
P\left[X(t)+Z(0)=1-\left[2 \pi \int_{0}^{t} \sigma^{2}(t) d t\right]_{0}^{-0.5} \int_{X(t)+Z(0)} \exp \left\{-\frac{\left[V(t)-\int_{0}^{t} \mu(t) d t\right]^{2}}{2 \int_{0}^{t} \sigma^{2}(t) d t}\right\} d V(t)\right.
$$

Assuming that in (3), $f[x(t)]$ is a square function of the $K=p x^{2}+q x+o$ type, from (9) we obtain:

$$
x(t)=(2 p)^{-1}\{a-(a+b) P[X(t)+Z(0)]\} t+C, \quad C-\text { const }
$$

and after the substitution of the expression given by the equation (16) into $\mathrm{P}[X(t)+Z(0)]$, the final form of the function of the distribution of the production in time is known.

As it results from the conducted analyses, the parameter standing at the time variable $t$ depends on the unit holding cost $h$, unit shortage cost $b$, and the parameters of the demand distribution.

\section{The case of many $q$ assortments}

The problems connected with the type of the production and the control of the production flows were widely discussed by Skowronek and Sarjusz-Wolski (1999). This article refers only to the mass production. The simultaneous production of many products results in the additional complications in the creation of optimisation models in the conditions of uncertainty.

\footnotetext{
3 In (14), the sum symbols were replaced by the integrals, because it was assumed that the random variables and their distributions are the continuous functions of the time variable $t$.

4 In (15), the lower integration limit was set as 0 - see the earlier substantiation.
} 
Let us assume that the demand and production are the continuous functions of the time variable $t$, which enables the construction of the following decision problem:

$$
\begin{aligned}
& W=\sum_{i=1}^{q}\left\{\int_{0}^{T} f_{i}\left[x_{i}(t)\right] d t\right\}+\sum_{i=1}^{q}\left\{\int_{0}^{T} h_{i} \int_{-\infty}^{Z_{i}(0)+X_{i}(t)}\left[X_{i}(t)+Z_{i}(0)-V_{i}(t)\right] \Phi_{i}\left[V_{i}(t)\right] d V_{i}(t) d t\right\}+ \\
& +\sum_{i=1}^{q}\left\{\int_{0}^{T} b_{i} \int_{Z_{i}(0)+X_{i}(t)}^{+\infty}\left[V_{i}(t)-X_{i}(t)-Z_{i}(0)\right] \Phi_{i}\left[V_{i}(t)\right] d V_{i}(t) d t\right\}+\sum_{i=1}^{q} \int_{0}^{T} g\left[x_{i}(t)\right] d t \rightarrow \min
\end{aligned}
$$

The extreme of the function (18) must be searched with the assumption that $Z_{i}(0), X_{i}(t)$, and $V_{i}(t),(i=1,2, \ldots, q)$ are non-negative, and knowing that:

$$
\begin{gathered}
Y_{1 i}(t) \leq X_{i}(t) \leq Y_{2 i}(t), \quad i=1,2, \ldots, q \\
\frac{\int_{m_{i}}^{n_{i}} x_{i}(t) d t}{\int_{m_{j}}^{n_{j}} x_{j}(t) d t}=t_{i j}, \quad i, j=1,2, \ldots, q, \quad i \neq j \\
Z_{i}(T)=e_{i} \geq 0, \quad i=1,2, \ldots, q
\end{gathered}
$$

Denotations:

$$
\begin{aligned}
& X_{i}(t)=\int_{t}^{t} x_{i}(t) d t-\text { production of the } i \text {-th product in the period }(0, t), \\
& \begin{aligned}
V_{i}(t)=\int_{0}^{0} v_{i}(t) d t & - \text { demand for the } i \text {-th product in the period }(0, t), \\
Z_{i}(0) & - \text { initial inventory of the } i \text {-th product, } \\
\ddot{O}_{i}\left[V_{i}(t)\right] & - \text { probability density function for the } i \text {-th product, } \\
h_{i}, b_{i} & - \text { unit holding and shortage cost of the } i \text {-th product, respectively, } \\
- & \text { function of the production cost of the } i \text {-th product, depending on the } \\
f_{i}\left[x_{i}(t)\right] & \text { production scale, } \\
- & \text { function of the production cost of the } i \text {-th product, connected to the } \\
& \text { production scale of all products, } \\
g\left[x_{i}(t)\right] & \text { coefficients of proportionality for production of the } i \text {-th and } j \text {-th } \\
& \text { products in the time intervals } n_{i}, m_{i} \text { and } n_{j}, m_{j}, \\
t_{i j} & \text { lower and upper limit of production of the } i \text {-th product in the period } \\
& (0, t) .
\end{aligned}
\end{aligned}
$$


The formula (18) presents the total costs of the company at the production of $q$ different products, as well as the total holding costs and the possible total shortage costs. The component $\sum_{i=1}^{q}\left\{\int_{0}^{T} f_{i}\left[x_{i}(t)\right] d t\right\}$ refers to the direct production costs connected with the use of materials, wages, labour time, etc. Therefore, they depend only on the production scale. The component $\sum_{i=1}^{q}\left\{\int_{0}^{T} h_{i} \int_{-\infty}^{Z_{i}(0)+X_{i}(t)}\left[X_{i}(t)+Z_{i}(0)-V_{i}(t)\right] \Phi_{i}\left[V_{i}(t)\right] d V_{i}(t) d t\right\}$ refers to the total holding costs of all the products in the period $(0, T)$. The component $\sum_{i=1}^{q}\left\{\int_{0}^{T} b_{i} \int_{Z_{i}(0)+X_{i}(t)}^{+\infty}\left[V_{i}(t)-X_{i}(t)-Z_{i}(0)\right] \Phi_{i}\left[V_{i}(t)\right] d V_{i}(t) d t\right\}$ refers to the possible total shortage costs in the analysed period. The remaining component $-\sum_{i=1}^{q} \int_{0}^{T} g\left[x_{i}(t)\right] d t$ denotes this part of the production costs that depend on the production scale of the whole company. This could be the costs that exist only at the specific number of assortments, as well as the company size, and, connected with this, the production size.

The introduced constraints (19) denote the upper and lower limits of the individual assortments in specific time intervals, dependent on both the orders scale and physical production capabilities. The conditions (20) enable the preservation of the appropriate proportions at the production of the individual products in specific time intervals, which is important at the orders significant for the course of the production processes in other companies, being both the suppliers and customers. Eventually, the conditions (21) are the postulates referring to the levels of the final inventories that the company should have in the moment of the end of the optimisation procedure.

Since the criterion function (18) is a set of integrals of the type:

$$
J_{i}=\int_{a_{i}}^{b_{i}} F_{i}\left[X_{i}(t), X_{i}^{\prime}(t), t\right] d t, \quad i=1,2, \ldots, q
$$

their subsequent solution by means of the Euler equations allows finding the suboptimal distributions of the production for the individual assortments. Therefore, the condition that must be satisfied in order to let the function $W$ reach the minimum, can be written in the form of the system of equations:

$$
\frac{\partial F_{i}}{\partial X_{i}(t)}=\frac{d}{d t} \frac{\partial F_{i}}{\partial X_{i}^{\prime}(t)}
$$


The left-hand side of equation (23) is as follows:

$$
\frac{\partial F_{i}}{\partial X_{i}(t)}=h_{i} \int_{-\infty}^{Z_{i}(0)+X_{i}(t)} \ddot{O}_{i}\left[V_{i}(t)\right] d V_{i}(t)-b_{i} \int_{Z_{i}(0)+X_{i}(t)}^{+\infty} \ddot{\mathrm{O}}_{i}\left[V_{i}(t)\right] d V_{i}(t), \quad i=1,2, \ldots, q
$$

while the right-hand side:

$$
\frac{d}{d t} \frac{\partial F_{i}}{\partial X_{i}^{\prime}(t)}=f_{i}^{\prime \prime}\left[x_{i}(t)\right] x_{i}^{\prime}(t)+g^{\prime \prime}\left[x_{i}(t)\right] x_{i}^{\prime}(t), \quad i=1,2, \ldots, q
$$

Analogously, as in (7), by introducing the substitution:

$$
\int_{Z_{i}(0)+X_{i}(t)}^{+\infty} \ddot{O}_{i}\left[V_{i}(t) d V_{i}(t)=P_{i}\left[Z_{i}(0)+X_{i}(t)\right], \quad i=1,2, \ldots, q\right.
$$

after the calculations, we obtain:

$$
x_{i}^{\prime}(t)=\left\{f_{i}^{\prime \prime}\left[x_{i}(t)+g^{\prime \prime}\left[x_{i}(t)\right]\right\}^{-1}\left\{h_{i}-\left(h_{i}+b_{i}\right) P_{i}\left[Z_{i}(0)+X_{i}(t)\right]\right\}, \quad i=1,2, \ldots, q\right.
$$

By solving subsequently $q$ differential equations (27), we can obtain $q$ functions of the distribution of the production in time for every of the produced products in the form of appropriate equations. The intercepts of these equations will depend on the constraints (19)-(21).

\section{Conclusions}

The question that should be put in the summary refers to the possibility of the application of the proposed solutions in practise. The considerations are theoretical and do not directly refer to their real use in companies. The use of stochastic conditions is certainly the step ahead with relation to the accepted before assumption about the full knowledge of the demand distribution. It would be necessary to collect the rich empirical data that would let us generate the demand distributions of the individual assortments. Also, the chance to create many variants of the distribution of the production in specific periods of time, and to select those that are convenient for the producer and the customers cannot be underestimated. The treatment of the obtained solutions as optimal is controversial. As a rule, the obtained solutions are not optimal, because they can be obtained only on the basis of the previously generated empirical distributions. 
However, they can be treated as quasi- or close to optimal. From the point of view of the practise, such status should be sufficient and acceptable.

\section{References}

Bronsztejn, I.N., Siemiendiajew, K.A., Musiol, G., Mühlig, H. (2004). Nowoczesne kompendium matematyki. Warszawa: Wydawnictwo Naukowe PWN.

Gelfand, M., Fomin, S. (1975). Rachunek wariacyjny. Warszawa: PWN.

Grzesiak, S. (2014). Wykorzystanie rachunku wariacyjnego do analizy wahań produkcji w przedsiębiorstwach. Studia i Prace WNEiZ US, 36 (1).

Lange, O. (1967). Optymalne decyzje. Warszawa: PWN.

Skowronek, Cz., Sarjusz-Wolski, Z. (2012). Logistyka w przedsiębiorstwie. Warszawa: PWE. 